\title{
LA TRASCENDENCIA EMPRESARIAL POST PANDEMIA "CONSTRUYAMOS UNA COMPAÑÍA QUE LA SOCIEDAD QUIERA QUE EXISTA"
}

\section{Amigo, Adriana}

\section{Resumen:}

Ya transcurridas, dos décadas del inicio del siglo XXI, nos enfrentamos a una realidad mundial, que moviliza los recursos y los objetivos empresariales a nivel mundial. Los mercados de consumo, se ven afectados por la pandemia declarada por la OMS, Covid 19, que impacta en los puestos de trabajo, en la movilidad de las empresas, en las culturas empresariales, pero mucho más en las personas. Y si cuando empezaba este siglo hablábamos que competir era transcender, hoy podemos afirmar que trascender es tan solo construir confianza en el frente interno y en el frente externo de las empresas. El mundo cambió y sólo se quedará con quien lo interprete, lo comprenda y lo respete. El desafío será formular, implementar y controlar una estrategia que haga que la empresa sea una compañía, que la sociedad quiera que exista.

Palabras claves: Confianza - Sociedad - Estrategia - Trascendencia - MovilidadRequerimientos

\begin{abstract}
:
After two decades of the beginning of the 21 st century, we ara faced with a global reality, which mobilizes resources and business objetives worldwide. Consumer markets are affected by de pandemic declared by the WHO, Covid 19, which impacts Jobs, company mobilty, business cultures, but much more to people. And if when this century began, we spoke that competingwas transcending, today we can affirm thar trascending es just building trust on the internal front and on the extermal front of conmpanies. The worl changen and it will only stay with those interpret, understan and respect it. The challenge wil be to formulate, implement and control a strategy that makes the company, that society wants it to exist.
\end{abstract}

Keywords: Trust - Society - Strategy - Transcendence- Mobility - Requirements 


\section{INTRODUCCIÓN}

"Este no será el siglo de un país en particular. Primero porque los cambios se suceden cada vez más rápido. Así que incluso si China se convierte en el número uno, puede que no dure un siglo en ese lugar de prevalencia. Creo que es demasiado sencillo afirmar que China será la próxima superpotencia o que India lo será. Creo más bien que viviremos una situación con una multiplicidad de superpotencias. No una, sino alianzas o grupos cambiantes, de países que, comparadas con su pasado, serán superpotencias"

Alvin Toffler- Revista La Nación-1ํ de febrero de 2009

En "Negocios con Valor" (Amigo; 2009) Amigo, expresa que competir es trascender. ¿Qué implica trascender?

Trascender es tras-pasar un límite común y situarse por encima de la media, con respecto a la posición de otros actores, jugadores, "dadores" de la característica, singularidad o simbología que genera la trascendencia.

Cabe preguntar:

- trascender, ¿para qué?

- trascender, ¿por qué?

- trascender, ¿para quién?

- trascender, ¿desde qué lugar?

Retomo esos planteos hoy, en plena pandemia mundial. Hoy, para identificar los cuestionamientos relativos a la Misión y a la Visión de la trascendencia, debemos pensar en las personas.

En un estudio cualitativo realizado este año por Consultora Market-MARKETING ESTRATÉGICO ${ }^{1}$, en el período comprendido entre abril y agosto de 2020, se analizaron los comportamientos de diez grupos motivacionales que fueron aglutinados por variables de conglomerado socioeconómicas y psicográficas. En este estudio, bajo mi Dirección, todavía no publicado, se detecta que el $66,50 \%$ de las personas entrevistadas, encuentra en el hogar, el principal centro de armonía interior y familiar. Ese sentimiento se acrecienta en el primer bimestre de medición y en el segundo bimestre de medición, se produce un comportamiento adaptativo de los grupos familiares, los que expresan en su $55,80 \%$ que la adaptabilidad se genera por adhesión y no por imposición. Al plantearles qué mejoró y que empeoró con el confinamiento, plantean los grupos familiares, en el $70 \%$ de los casos, que ha mejorado la propensión a la buena convivencia que luego impacta en la sensación de bienestar, ha bajado la dependencia hacia marcas relacionadas con propuestas de

\footnotetext{
${ }^{1}$ Amigo, Adriana. Consultora Market - Marketing Estratégico. Estudio Cualitativo. Impacto del Confinamiento en los Comportamientos. Período de Ejecución (Abril-Agosto 2020) Variables de conglomerado utilizadas: variables socioeconómicas y psicográficas
} 
valor que impactan en el posicionamiento personal, mejoran los hábítos y la conciencia del ahorro, se retomaron prácticas de entretenimiento familiar participativo y la creatividad se percibe como un hábito que se construye, entre todos los componentes del grupo familiar en un $60 \%$, entre subgrupos de pares (padres, hermanos, compañeros de trabajo en home office) $30 \%$ y de manera individual $10 \%$.

Esto es tan solo un adelanto, de lo que se analizó en el seguimiento de 10 grupos motivacionales, los que se aglomeraban por variables psicográficas y socioeconómicas, es decir, los conglomerados se armaron con distanciamiento natural de variables, pero esas variables que distancian los conglomerados, no se manifiestan luego en distancias comportamentales.

Esto nos está manifestando, cambios estructurales que se generaron en el transcurso de un semestre de vida de las personas, tal como si esto hubiera sido una prueba de laboratorio, con dos características: cambios profundos y cambios rápidos, impactando de manera trascendentales en nuevos comportamientos en los grupos de pertenencia de las personas.

Entonces en términos competitivos, lo que Amigo (2009; 2012; 2017) escribe en "Negocios con Valor" está más vigente que nunca: trascender es perdurar en el compromiso de brindar de manera continua "valor" a "un determinado grupo de personas" que deberá convertirse en "el grupo aglutinador del valor de la compañía" (GAV). A esta apreciación deberíamos agregarle una reflexión, esos GAV, ya no son los mismos, luego las empresas deberán comenzar ya a replantear sus negocios.

Competir en el siglo XXI no es fácil. Es singular. (2017) Y es un desafío que merece replantear algunas filosofías, a las que le agregamos una filosofía irrenunciable: el conocimiento, el que deberá sustentarse en la credibilidad social. Todas esas filosofías, han tomado frente a los nuevos escenarios, el protagonismo irrenunciable de beneficiar al mercado desde prácticas éticas, sustentables y socialmente comprometidas:

- La filosofía de la innovación

- La filosofía del conocimiento basado en la credibilidad social

- La filosofía de la flexibilidad

- La filosofía de la diferenciación

¿Por qué el siglo XXI, y en especial hoy año 2020, necesita de innovación, conocimiento, flexibilidad, diferenciación, reconocimiento, trabajo en equipo, respeto por el sector industrial y credibilidad social?

Pues venimos de un siglo en donde muchas de esas filosofías se diluyeron y entramos a este siglo con una humanidad desilusionada, separada, quebrantada, no reconocida, 
con sectores no incluidos, no pertenecientes a ningún proyecto, muchas individualidades y pocas ideas compartidas, miedo a no contar, miedo a ser copiados, miedo a la pérdida del lugar, todos sentimientos y actitudes cortoplacistas que impiden la trascendencia. (Amigo, 2017) y hoy estamos viviendo este siglo aprendiendo a interactuar con la incertidumbre, el compromiso social y escenarios de crisis.

Han cambiado los miedos de las personas, cerrando mi primer edición de "Negocios con Valor" (2009) identificaba uno de los miedos más profundos de las personas y de las marcas, al miedo a no ser reconocidos. asumiendo caminos, objetivos y políticas equivocados y cortoplacistas. mientras algunas empresas buscaban bajar el precio para competir y atentaban contra el desarrollo de competencias centrales, cada vez más, algunas grandes, medianas y hasta pequeñas empresas intentaban tan sólo acostumbrar a la demanda a un dos por uno promocional, no asumiendo el error de la parálisis creativa y algunas personas compraban sujetos con objetos y se olvidaban de su esencia. (2012)

Entonces deberemos plantearnos cómo se habrán de transformar las filosofías competitivas para generar valor y desarrollar ventajas competitivas sostenibles.

\section{LA FILOSOFÍA DE LA INNOVACIÓN}

Si innovar es replantear o modificar un status quo, la filosofía de la innovación le plantea a la compañía la posibilidad de hacer, deshacer, rehacer vínculos, servicios, productos, relaciones, metodologías y por supuesto impactar positivamente en la tasa de retorno desde este replanteo. Amigo(2009;2012;2017)

Pero el hacer, deshacer y rehacer, hoy comienza con la nueva normalidad, en la que los nuevos hábitos de convivencia social, son esenciales a la preservación de la vida humana.

En el preconcepto de que la innovación es tan sólo tecnología y que la tecnología es cara, y que sólo podrían ser innovadoras todas aquellas organizaciones que pudieran acceder al recurso "tecnología", hoy más que nunca, innovar es atreverse a cambiar, pero imperiosamente, pues un minuto de error, es hoy una tasa de contagio de $10 \%$ y una duplicidad de casos menor a 10 días.

Innovar es cambiar la concepción de nuestros destinatarios y el punto de partida es comprender que la empresa formulará una estrategia en pos del crecimiento, basada en la modificación e introducción de nuevos conceptos, productos, servicios, y por ende, valores, teniendo en cuenta los cambios estructurales en los comportamientos de los consumidores y los mercados. John Buckley, en "Cómo crecer con ventaja competitiva", establece que los retornos comienzan a disminuir cuando los productos y servicios no se regeneran, porque en la detención del horizonte creativo, los mercados 
terminarán por olvidar qué valor ofrecían determinadas marcas: si hoy le preguntáramos a nuevos jóvenes consumidores sobre marcas como Singer, por ejemplo, no podrían contestar absolutamente nada. Buckley, John (1997; 67). La reflexión de Buckley, nos lleva al camino de que la innovación es la capacidad de la empresa de adaptarse y reacción ante los cambios comportamentales.

La necesidad de innovación en el 2020, vino dada por la urgencia de brindar valor, en una realidad distinta, en la que estaba muy claro que habían cambiado profundamente los códigos de comunicación con alto impacto en la rentabilidad.

¿Cómo iniciar este proceso imprescindible y diferenciador? Para poder cambiar, es decir, para poder ser actores y generadores del cambio, debemos motivar en las personas a quienes conducimos a ese cambio, la posibilidad de poder atreverse al error, la libertad de crear sin miedo a ser imitados con empatía por el destinatario de la propuesta de valor. Amigo $(2009 ; 2012 ; 2017)$ habla de la conjunción de valores compartidos:

- Libertad: las ideas deben fluir y el escenario correcto comienza con la libertad de expresarlas.

- Confianza: la credibilidad en el equipo de trabajo receptor y productor, es una condición necesaria para que estas nuevas ideas, desarrollen nuevos conceptos, productos, servicios, en nuevos escenarios.

- Compromiso: debe ser fuerte la responsabilidad por plasmar las ideas en resultados, pues las dificultades que la innovación implica, muchas veces impiden llegar a feliz destino.

- Liderazgo: la innovación necesita de un líder de proyecto que haga que todos caminen hacia el mismo objetivo, cualquiera sea la función y el rol que ocupen.

- Valor: en la post modernidad y en el siglo XXI, con una sociedad fragmentada, será necesario medir el nivel de requerimiento del valor, en consecuencia, la adecuabilidad será una condición para que el valor fluya hacia el mercado y el destino correcto.

- Estructura: la innovación requiere de una estructura organizativa acorde al proyecto, para que las ideas formuladas se implementen, y se controlen las actividades implicadas en el cumplimiento de esos objetivos.

\section{LA FILOSOFÍA DEL CONOCIMIENTO BASADO EN LA CREDIBILIDAD SOCIAL}

"Ganarse la vida ya no basta. El trabajo también debe crear una vida". Peter Drucker. "La Gerencia" Amigo (2009; 2012; 2017) 
Los cambios que precedieron al siglo XXI, explicaban según Peter Drucker (1994) en "La Gerencia" la aparición de una nueva clase de trabajador: los jóvenes muy educados, que en los países desarrollados se oponían a la administración tradicional del trabajo y los trabajadores, pero que como consecuencia del conocimiento, estaban mejor educados y mejor pagados, sintiendo su descenso de la antigua condición de digno integrante de la clase trabajadora a la de un ciudadano de segunda clase.

Es importante analizar, que estos cambios produjeron el nivel ascendente de las expectativas más que el bienestar y que entonces el conocimiento con su nueva y mal definida jerarquía social, esperaba que el trabajo aportara satisfacciones sociales psicológicas no materiales. Amigo (2009; 2012; 2013)

En los inicios del siglo XXI, el conocimiento ¿generó anclajes o desanclajes? Anthony Giddens, (1994) en "Consecuencias de la modernidad" expresa que tras los efectos de la modernidad, mucha gente vive en circunstancias en las que las instituciones desancladas, que enlazan las prácticas locales con las relaciones sociales globalizadas, organiza importantes aspectos del vivir de cada día. Este principio citado por Amigo (2009; 2012; 2017) cobra hoy, en setiembre del 2020, una realidad y trascendencia inobjetable, pues se produce el efecto contrario e inverso del anclaje y desanclaje del que habla Giddens, las personas de están desanclando de las relaciones sociales globalizadas (Disminución de ventas de ticket aéreos internacionales, la industria del turismo mundial está sufriendo la crisis más importante de los últimos tiempos, la tienda Zara ha cerrado más de 700 tiendas en el último bimestre), ya que el anclaje se produce en las famosas sociedades de encierro en donde se manifiesta el vivir de cada día.

Cuando Mario Heler, (2005) manifestaba en "Entre la producción y la acreditación" que en la sociedad actual en transición en la que al conocimiento no se lo puede asociar solamente con el saber científico, los avances de la tecnociencia profundizan el conflicto fuera y dentro del campo científico. Deberíamos preguntarnos qué nuevos conflictos se plantearán hoy fuera y dentro del campo científico.

Amigo (2009; 2012; 2017) plantea que el siglo XXI había sorprendido en sus inicios, comunicados con los finales del siglo $X X$, con escenarios amenazantes a los anclajes sociales del valor: el riesgo de guerra nuclear o de catástrofe ecológica; el sida; el síndrome de influenza; la imposibilidad de algunos sectores sociales de acceder a aspectos fundamentales de la calidad de vida como la salud, la libertad o la dignidad, por ejemplo, nos hacen reflexionar si en el siglo XXI no deberíamos revertir el concepto del conocimiento en mano de unos pocos, para convertirlo en estructuras fiables de convivencia pacífica. 
La sociedad necesita confiar y la comunidad científica debe arbitrar los medios para que esa confianza fluya y el hombre pueda sentirse contenido en relaciones de credibilidad.

Esto implica por parte de esta comunidad, un compromiso con la norma bajo la cual la ciencia se produce, con la producción de saberes, con su acreditación, pero fundamentalmente con el hombre.

A su vez, (2009; 2012, 2017) Giddens (1994) nos habla de compromisos presenciales, que interrelacionan a la sociedad del conocimiento en relaciones de fiabilidad y confianza, que implican que mientras un grupo de representantes tienen el crédito social por su "conocimiento" (profesionales en general), otro grupo estará destinado a depender de la apariencia que ese conocimiento ostenta. ("las solemnes deliberaciones de un juez; la sobria profesionalidad de un médico, o el tópico buen humor y amabilidad de la tripulación de vuelo, caen dentro de esa categoría")

Retomo mi propio plateo $(2009$; 2012; 2017) y lo enfoco en situación de espacio y tiempo ¿hoy en el escenario mundial atravesado por el covid 19, trascenderemos "por" el conocimiento, "para" el conocimiento o "después" del conocimiento? O ¿deberemos sostener a la competitividad en el real anclaje social, basado en la credibilidad, la ética y la acreditación?

Si según Giddens, la ignorancia proporciona siempre el terreno para el escepticismo o por lo menos para la cautela, ¿por qué no comenzar por poner al conocimiento en beneficio y a disposición de la sociedad para que los enfrentamientos sociales, culturales y políticos, no nos quiten tiempo a la urgencia de la solución esperada?

Las estructuras sociales del siglo XXI (familia, escuelas, universidades) en donde se transmiten los primeros y finales principios fiables del conocimiento, han debido cambiar sus estructuras en su planificación, formulación, implementación y control. Hoy ya no nos planteamos si estamos forjando desde la escuela, un consumidor responsable, hoy lo exigimos, pues la vida misma está en riesgo sin ese principio de responsabilidad individual

Amigo (2009; 2012; 2017) comenta que Nazim V. Burke, Ministro de Finanzas y Comercio Exterior de la pequeña isla de Granada, Islas Occidentales, habla de la necesidad de la transferencia de conocimientos - mediante la cual un país desarrollado o una empresa transmite saber hacer y competencias técnicas a un país menos desarrollado - contando como caso positivo el ejemplo de una pequeña fábrica de chocolate en donde la calidad se aproxima a la mejor del mundo. $Y$ es una instalación de tan sólo tres o cuatro trabajadores, alimentada con energía solar que tiene un muy rentable mercado de exportación en Europa. 
Este ejemplo de transparencia debería repetirse más frecuentemente o debería por lo menos estar planificado en los planes de accesibilidad y transferencia tecnológica de los países desarrollados a los países emergentes: Nazim V. Burke, (2008) dice que: "Debería haber un modo de enseñar a pescar a los pueblos del Tercer Mundo, de los países en desarrollo, en lugar de limitarse a darles un pescado cada vez que tiene hambre"... ."

Entonces, ya no es suficiente alcanzar el conocimiento, se necesita compartirlo, transferirlo y aplicarlo a los genuinos requerimientos sociales, en beneficio de la libertad y de la dignidad, para que su evolución y desarrollo no acreciente los desanclajes y quiebres en los pueblos y las naciones, para que el hombre no sienta que aun cuando internalice y aprenda, se sienta cada vez más lejos de sus posibilidades por las que se capacitó. Amigo (2009; 2012; 2017)

\section{LA FILOSOFÍA DE LA FLEXIBILIDAD}

Las circunstancias competitivas, en donde se gestan los negocios en el siglo XXI, son tan cambiantes y a un ritmo tan fuerte, que podríamos decir que la flexibilidad nace y se desarrolla como respuesta a un contexto de cambio. (2009; 2012; 2020) Ahora bien, como aplica este principio al escenario de pandemia mundial decretado por la OMS.

Si la flexibilidad implica, la adaptabilidad a nuevos escenarios, este año significó para empresas y mercados, la incertidumbre como plataforma, la desaparición de los contactos sociales presenciales y el nacimiento de una nueva forma de comunicar frente a los transmisores vectores del virus del Covid 19. Hoy quienes no se flexibilizaron, ya no están. Alvin Toffler (La Nación; 2009) en una entrevista concedida para Revista La Nación en febrero de 2009, expresaba que ya el cambio no es lineal, que su dirección puede variar hacia atrás, hacia adelante o hacia los costados.

Desde esta limitación, de un contexto cada vez más incontrolable, la flexibilidad también amortigua el impacto del cambio, pues permite la cultura de la reacción versus la información que ese impacto genera, administrándola en beneficio de la toma de decisión. Amigo (2009; 2012; 2017)

Voy a contradecirme a mí misma, expresaba en "Negocios con Valor" que

la flexibilidad no se construye en el corto plazo, pues los mayores impedimentos a la flexibilidad tienen que ver con los decisores, con las personas y con la cultura organizativa en donde dicha flexibilidad se potencia o se imposibilita. Este principio, tiene que ver con que la flexibilidad implica un cambio en la cultura empresarial que para que se dé, desde el aprendizaje, debe insertarse y construirse metodológicamente, sin embargo, la pandemia nos obliga a flexibilizar ya ahora, lo que 
significa que el impacto en los cambios comportamentales serán determinantes de nuevas realidades, nuevas definiciones de negocios, nuevas oportunidades, nuevas amenazas, nuevas empresas.

¿Y esto qué significa? Significa agregar el prefijo "re" a las definiciones empresariales. Pues la flexibilidad facilita distintas lecturas, y a partir de las distintas lecturas afloran las oportunidades de negocios. ¿Por qué? Porque en un mercado en donde en la mayoría de los sectores industriales hay más oferta que demanda, las oportunidades están naturalmente disminuidas, entonces se necesitan más consideraciones, otras tantas más interpretaciones a los números, a las estadísticas, a los comportamientos, para encontrar los caminos a través de los cuales se inyectarán valores genuinos a clientes genuinos.

Es la espiral re-cíclica del crecimiento en alternativas competitivas diferentes, porque la aptitud al crecimiento es más que nada una actitud, no depende solamente de la posesión y nivel de recursos hard, también la propensión a crecer, necesitará anclarse en los recursos soft. Amigo (2009; 2012; 2017)

Y esta concepción, lleva a pensar que la dimensión del tamaño de empresa no depende de la dimensión de provisión de recursos. Pues estos recursos aumentan o disminuyen de valor en función de su posibilidad de desarrollo interno y es en las culturas adaptativas, en donde mejor se desarrollarán las competencias centrales.

\section{LA FILOSOFÍA DE LA DIFERENCIACIÓN}

¿Cuál es la mejor posición para fijar los precios de los productos y/o servicios en condiciones competitivas? Amigo (2009; 2012; 2017)

La mayor discrecionalidad de oferta se da en situación de monopolio, en la cual el competidor puede fijar el precio que quiere, cubriendo todos sus costos, con el margen de rentabilidad asegurado y que además no haya ningún otro competidor obstaculizando su discrecionalidad.

Pero en esas condiciones es difícil lograr la equidad. Siempre alguien pierde. Lo difícil y amenazante es que pierdan los actores de un sector industrial que dan valor, movimiento y competitividad a dicho sector: empresas lácteas versus tamberos, Estado versus docentes, exportadores versus importadores, aceiteras versus oleaginosas. Los actores de un sector industrial son socios, deben ser socios, son clientes internos, son clientes externos y como tales deben reconvertir sus tasas de retorno como en vasos comunicantes.

¿Y esto cómo es posible?: Que cada actor actúe y sea protagonista, que cada competidor gane la lealtad de sus clientes. ¿Se gana la lealtad de los clientes?: Tanto como el respeto entre las personas, termina siendo una relación de afecto en donde el 
precio es un precio de valor y la demanda es insensible al mismo. ¿Por qué? Porque la diferenciación permitió establecer una relación en donde el todo es mayor que la suma de las partes: el todo que recibe el consumidor por el precio que paga, versus el todo que brinda la empresa por el producto y/o servicio que cobra.

¿Qué significa diferenciación?

Significa que el valor, (tanto en el concepto restringido como ampliado de producto y/o servicio) que ofrece una marca, será percibido como único por el mercado, entre los competidores que lo están brindando. La calificación ÚNICO, NO ES MENOR, SIGNIFICA IRREMPLAZABLE, esto es: el cliente, la demanda está dispuesta a realizar cualquier esfuerzo con tal de alcanzar y disponer de ese beneficio.

Cuando esta relación es estable, la discrecionalidad de la oferta es equitativa o superior a la discrecionalidad de la demanda y desde la rentabilidad que dicha relación ventajosa le genera, la empresa podrá ser una fuente única y continua generadora de valor.

Entonces, la continuidad de la provisión de valor, origina demanda leal, la demanda leal desarrolla ventajas competitivas sostenibles, las ventajas competitivas sostenibles, generan tasa de retorno superior a la tasa promedio de la industria, esta posición permite el crecimiento estable y en ese logro, la empresa habrá contribuido en parte con su responsabilidad social organizacional.

En el siglo XXI, y ante la actual crisis financiera, económica, social, mundial, ¿en dónde se sientan las bases de una diferenciación exitosa?

La diferenciación tiene un objetivo estratégico que es el de posibilitar a la empresa un posicionamiento estable en mercados leales que se sienten satisfechos por la singularidad que dicha estrategia implica.

Cómo expresa Patricia Francis, Directora Ejecutiva del ITC (International Trade Centre) en las conclusiones del Foro Mundial para el desarrollo de las Exportaciones 2008 (Suiza), "a fin de intensificar la cuota de mercado de mercancías éticas de países en desarrollo, es necesario examinar la cadena global de suministro y ver dónde coincide, o puede coincidir, con la capacidad de suministro global y ajustar las estrategias de negocios en consecuencia. Esta es la única manera que tenemos (en las economías en desarrollo y en transición) de obtener mejores cuotas de mercado." ¿Por dónde pasarán los vínculos reales y estables entre marcas y consumidores? Hoy la preocupación, ya no sólo pasa por no acceder o poder pagar, sino que el consumidor está realmente preocupado y motivado por cuestiones más trascendentes. Así como desde hace ya un tiempo a esta parte los consumidores relacionan la salud con lo que comen, muchos se preguntan qué impacto tiene en el medio ambiente los insumos que están en los productos que consumen, por ejemplo la indumentaria. 
Estas son las nuevas fuentes de sustentabilidad de los negocios en el siglo XXI, la "calidad" del vínculo con los consumidores, que traspasando barreras socioeconómicas, aglutinan su comportamiento alrededor de valores claves que le importan a todos más o menos por igual: esto ha hecho por ejemplo que la demanda de algodón orgánico en la industria textil supere a la oferta y que los "dadores" de esa singularidad, obtengan grandes beneficios. Si bien la producción de algodón orgánico es más cara, cada vez son más los consumidores dispuestos a pagar un suplemento para reducir el impacto ambiental.

Entonces, desde la identificación de un real y distinto requerimiento: "usar indumentaria cuya materia prima no contamine el medio ambiente", quizás no tan común como el simple deseo de "vestirse", pasamos de una situación competitiva en donde antes había más oferta que demanda, luego el GAV (Grupo aglutinador de valor) no aparecía y ahora hay más demanda que oferta, con la insensibilidad al precio que esa situación determina, apareciendo un GAV que se aglutina alrededor de "valores sociales no tradicionales o comunes"

A estas situaciones planteadas por las responsabilidades del consumidor, preocupado por la calidad de vida, nos damos cuenta, que esos principios fueron insuficientes para prevenir una pandemia, con lo que será muy fácil o muy difícil, según sea la mirada de la empresa hacia el mercado, el nuevo concepto de diferenciación, pues el mundo es otro y sólo se quedará con quien lo interprete, lo respete y lo mejore. ¿Estaremos a la altura?.....

\section{CONCLUSIONES}

- La permanencia en los mercados, se ha puesto en tela de juicio. En consecuencia la rentabilidad no está asegurada y su impacto en la provisión de valor será determinante.

- Lo que facilitará la permanencia en los mercados, será el cambio de actitud de las empresas, las que más que nunca deberán definir sus negocios pensando no solo en el negocio de la satisfacción sino en las insatisfacciones generadas por el negocio de la satisfacción.

- No será un proceso corto ni accesible, salvo que lo que más se adecúe a la accesibilidad sea la nueva empresa, el refundar el concepto de liderazgo, el replantear que las decisiones no pueden ser tomadas por una sola visión puesto que en estas decisiones la empresa se juega la vida, la de su marca, la de sus personas, la de sus clientes. 
- La marca deberá construirse sobre una credibilidad de largo plazo, en la que la medición de la calidad contrasta con el bienestar genuino de sus destinatarios, sea otra estrategia empresarial en sí misma.

- La vulnerabilidad es de todos, la oportunidad es de todos, la amenaza es de todos, la posibilidad de ser identificado como la mejor propuesta de valor, está en poder de quienes interpreten los requerimientos del mercado, lo respeten y lo mejoren.

\section{REFERENCIAS BIBLIOGRAFÍCAS}

Amigo, Adriana. (2009): Negocios con Valor, $1^{\circ}$ Edición. Fundación Ross, Argentina. Amigo, Adriana. (2012): Negocios con Valor. $2^{\circ}$ Edición. Fundación Ross, Argentina. Amigo, Adriana. (2017): Negocios con Valor, Edición Europea. Editorial Académica Española. España. Madrid.

Buckley, John V., (2000): Cómo crecer con ventaja competitiva. El valor real de la Tecnología. Mc Graw Hill. Colombia.

Carrión Marotto, Juan. (2007): Estrategia, de la visión a la acción. Alfaomega, ESIC, España.

Drucker, Peter F., (1998): La Gerencia. Tareas, responsabilidades y prácticas.6ํㅡㄴ Edición. El Ateneo. Buenos Aires. Argentina.

Gibson, Rowan y otros, (1997): Repensando el futuro, Grupo Editorial Norma, Bogotá. Colombia.

Harvey, David. (1998) La condición de la posmodernidad. Investigación sobre los orígenes del cambio cultural. Amorrortu. Buenos Aires, Argentina. Hamel, Gary; Prahalad, G.K.(1999) Compitiendo por el futuro, Editorial Ariel, Sociedad Económica, $2^{\circ}$ reimpresión, Barcelona. .

Giddens, Anthony. (1994) Consecuencias de la modernidad. Alianza. Madrid, España.

Heller, Mario. (2005) Entre la producción y la acreditación. Cuadernos del SurFilosofía. Neuquén. 